http://ejournal.upi.edu/index.php/jaz/ - e-mail: jurnal.zonasi@gmail.com dan jurnal zonasi@upi.edu DOI: http://10.17509/jaz.v2i1.15062

\title{
MITIGASI SPASIAL TERHADAP BENCANA SOSIAL DI PERMUKIMAN JOHAR BARU, JAKARTA PUSAT
}

$$
\begin{aligned}
& \text { Article History: } \\
& \text { First draft received: } \\
& 21 \text { Januari } 2019 \\
& \text { Revised: } \\
& 26 \text { Januari } 2019 \\
& \text { Accepted: } \\
& \text { 5 Januari } 2019 \\
& \text { Final proof received: } \\
& \text { Print: } \\
& \text { 10 Februari } 2019 \\
& \text { Online } \\
& 11 \text { Februari } 2019
\end{aligned}
$$

\section{Made Suryanatha Prabawa ${ }^{1}$ \\ Wita Indriani ${ }^{2}$ \\ Heni Dewiyanti ${ }^{3}$}

${ }^{1}$ Teknik Arsitektur, Universitas Warmadewa

Jalan Terompong no. 24, Denpasar, Indonesia

${ }^{2}$ Dinas Perumahan Rakyat dan Kawasan Permukiman Provinsi DKI Jakarta,

Jalan Taman Jatibaru no. 1, Jakarta Pusat, Indonesia

${ }^{3}$ Konsultan Publik,

Bintaro Jaya-Sektor 4, Jakarta, Indonesia

Email: prabawa@warmadewa.ac.id wita.indri@gmail.com heny.dewiyanti@icloud.com

Abstract: Sosial disasters is a disaster caused by event involving humans such as sosial conflicts between groups or between communities, and terror. Johar Baru Sub-District is famous as a sub-district with an average population density of 60.433 person $/ \mathrm{km}^{2}$. These conditions make it included as the most densely populated residential area in Southeast Asia. The population density in it's settlements was exacerbated by riot action through brawls between youngsters/teenagers gank in Johar Baru Sub-District. This research try to explore and find the actual cause of the brawls that can occur with related studies to it's surrounding densely urban residential environment. Several literatures were used such as (1) personal space and crowdings; (2)environmental stress, stress, and coping strategy; (3)sosial exclusion; and (4) Causes of Conflicts Theory. The Research is descriptivequalitative with primary and secondary data analysis. Research shows that the conditions of spatial density in the Johar Baru Settlement is quite dense especially in the Kampung Rawa and Galur Village (Kelurahan). Examples of homes in slums area also indicate the cause of brawl can occur. Identification of hangouts and brawls also shows brawls as sosial disasters that need to be followed up. Spatial mitigation as a solution is carried out with the principle of mobile and flexible. The principle was formulated in the form of a mobile architecture and vertical garden as a solution of spatial utilization in the homes of residents who can reduce the intensity of brawls by presenting useful new activities.

Keywords: Population Density; Brawl; Spatial Mitigation

Abstrak: Bencana tidak hanya sebatas bencana alam, namun juga terdapat bencana yang disebabkan oleh manusia. Salah satu bencana yang disebabkan oleh manusia adalah bencana sosial. Bencana sosial adalah bencana yang disebabkan oleh peristiwa yang melibatkan manusia seperti konflik sosial antar kelompok atau antar komunitas masyarakat, dan terror. Kecamatan Johar Baru terkenal sebagai kecamatan dengan tingkat kepadatan penduduk rata-rata $60.433 \mathrm{Jiwa} / \mathrm{Km}^{2}$. Kondisi tersebut membuatnya termasuk sebagai wilayah permukiman terpadat se-Asia Tenggara. Kepadatan penduduk dalam permukimannya tersebut diperparah dengan terkenalnya Johar Baru sebagai wilayah Tawuran antar geng Remaja. Penelitian ini mencoba menggali penyebab tawuran tersebut dapat terjadi terkait dengan kondisi densitas spasial yang tinggi, disusul dengan memberi solusi mitigasi dalam bentuk mitigasi spasial berbasis ilmu arsitektur. Didalam menggali isu penelitian ini, terdapat beberapa literatur yang dipergunakan seperti (1) personal space \& crowding; (2) tekanan lingkungan, stress dan coping strategy; (3)eksklusi sosial,; dan (4)teori penyebab konflik. Penelitian bersifat deskriptif-kualitatif dengan metode analisa data primer dan sekunder. Penelitian menunjukkan bahwa kondisi densitas spasial di 
Permukiman Johar Baru cukup padat khususnya pada Kelurahan Kampung Rawa dan Galur. Contoh rumah tinggal pada kawasan kumuh juga mengindikasikan sebab dari tawuran dapat terjadi. Identifikasi titik-titik nongkrong serta tawuran juga memperlihatkan tawuran sebagai bencana sosial yang perlu untuk ditindaklanjuti. Mitigasi spasial sebagai solusi dilakukan dengan prinsip mobile dan fleksibel. Prinsip tersebut digubah dalam bentuk mobile architecture dan vertical garden sebagai solusi pemanfaatan spasial didalam lingkungan rumah warga yang dapat mengurangi itensitas tawuran dengan menghadirkan kegiatan baru bermanfaat

Kata Kunci: Kepadatan Penduduk; Tawuran; Mitigasi Spasial

\section{Pendahuluan}

Menurut UU Republik Indonesia No. 24 Tahun 2007 menyebutkan bahwa bencana adalah suatu rangkaian peristiwa yang mengancam dan dapat menganggu kehidupan atau penghidupan masyarakat masyarakat. Penyebabnya dapat berupa faktor alam maupun non alam dan juga faktor manusia, kerusakan lingkungan, kerugian harta benda, dan dampak psikologis. Bencana non alam adalah bencana yang disebabkan oleh peristiwa non alam seperti gagal teknologi, gagal modernisasi, epidemic, dan wabah penyakit. Bencana sosial adalah bencana yang disebabkan oleh peristiwa yang melibatkan manusia seperti konflik sosial antar kelompok atau antar komunitas masyarakat, dan teror.

Terdapat sebuah wilayah padat di Jakarta Pusat yakni Kecamatan Johar Baru yang terkenal pula akan kekumuhan dan konflik sosial. Secara Geografis, Johar Baru terletak di Jakarta Pusat dan merupakan satu Kecamatan hasil pemekaran Kecamatan Cempaka Putih. Wilayahnya terbagi kepada 4 (empat) kelurahan yaitu Johar Baru, Kampung Rawa, Tanah Tinggi, dan Galur. Berdasarkan Data Johar Baru Dalam Angka (2018), Kecamatan Johar Baru mempunyai Rukun Warga (RW) sebanyak 40 RW, dan Rukun Tetangga (RT) sebanyak 558 RT. Kecamatan Johar Baru, mempunyai luas wilayah $2.37 \mathrm{Km}^{2}$, dengan jumlah penduduk yang tercatat sebanyak 143.227 jiwa, dan kepala keluarga sebanyak 45.526 jiwa. Berdasarkan jumlah penduduk tersebut laki-laki sebanyak 72.623 jiwa, dan perempuan 70.604 jiwa. Dengan luas wilayah dan jumlah penduduk tersebut, maka tingkat kepadatan penduduk di kawasan itu rata-rata $60.433 / \mathrm{Km}^{2}$. Berdasarkan data kepadatan tersebut Johar Baru termasuk sebagai kawasan permukiman terpadat se-Asia Tenggara.

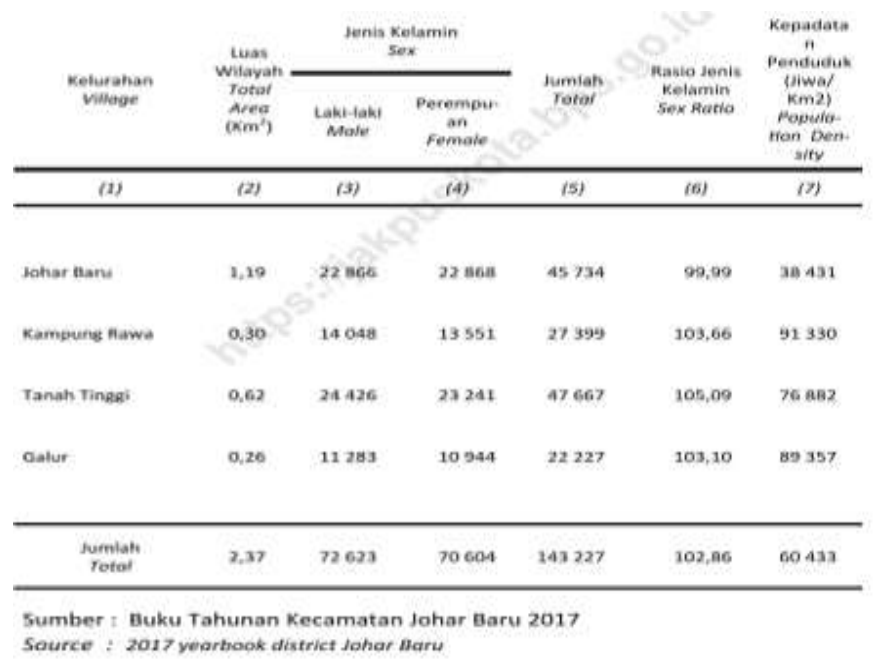

Gambar 1.1 Data Kependudukan Kecamatan Johar Baru Sumber: Johar Baru Dalam Angka, 2018

Permukiman Kumuh Johar Baru identik dengan sebutan kampung tawuran oleh warga sekitar Jakarta, akibat intensitas tawuran yang terjadi di wilayah ini cukup sering (https://www.suara.com/news/2017/12/07/005213). Cloward dan Ohlin (1960, dalam Darmajanti, Wirutomo, Ery Seda, dan Yasmine, 2012) menyebutkan bahwa berbagai perkumpulan anak muda laki-laki menunjukkan bahwa geng yang melakukan tindak kekerasan tumbuh dan berkembang dalam subkultur komunitas yang kecenderungannya memiliki kesulitan mencapai kesejahteraan kehidupan. Didalam kajian mengenai arsitektur, lingkungan, dan perilaku dapat dipahami secara lebih komprehensif melalui isu-isu yang berkaitan 
dengan tekanan lingkungan (environmental pressures, stress), serta strategi penanganannya (coping strategy). Tekanan lingkungan adalah faktor-faktor fisik, sosial, serta ekonomi yang dapat menimbulkan perasaan tidak enak, tidak nyaman, kehilanagan orientasi, atau kehilangan keterikatan dengan suatu tempat tertentu (Haryadi, 2014). Jika hal ini dibiarkan maka akan berdampak pada timbulnya stress. Tekanan lingkungan yang terlalu besar menyebabkan interaksi antar manusia dan dengan lingkungannya tidak berjalan secara optimal-sehingga berbuntut pada perilaku yang tidak wajar (akibat stress). Coping strategy adalah salah satu strategi individu dalam penanganan stress akibat tekanan- tekanan yang mengancam diri individu, strategi dilaksanakan dengan memanfaatkan sumber daya yang ada untuk mengurangi tingkat stress yang dialami. Berdasarkan tinjauan pengggalan tersebut, perlu untuk menemukan solusi terkait tindakan mitigasi yang harus diambil. Solusi penanggulangan secara spasial (pendekatan ilmu arsitektur) berusaha untuk dihadirkan dengan tujuan mampu mengurangi intensitas Konflik horizontal tawuran di permukiman kumuh Kecamatan Johar Baru ini.

\begin{tabular}{|c|c|c|}
\hline $\begin{array}{c}\text { Kelurahan } \\
\text { Village }\end{array}$ & $\begin{array}{c}\text { Jumlah Lokasi } \\
\text { Pemukiman Ku- } \\
\text { muh } \\
\text { Number of Slum } \\
\text { Area }\end{array}$ & $\begin{array}{l}\text { Jumlah Rumah } \\
\text { Tangga yang } \\
\text { Menetap di Pem- } \\
\text { ukiman Kumuh } \\
\text { Number of House- } \\
\text { hold Who Lived in } \\
\text { Slum Area }\end{array}$ \\
\hline (1) & (2) & (3) \\
\hline Johar Baru & 2 & 1458 \\
\hline Kampung Rawa & 1 & 714 \\
\hline Tanah Tinggi & 4 & 2443 \\
\hline Galur & 2 & 920 \\
\hline $\begin{array}{c}\text { Jumlah } \\
\text { Total }\end{array}$ & 9 & 5535 \\
\hline
\end{tabular}

Gambar 1.2 Lokasi Permukiman Kumuh dan Rumah Tangga Yang Menetap di Kecamatan Johar Baru. Sumber: Johar Baru Dalam Angka, 2018

Menurut Darmajanti (2012), akar masalah tawuran disebabkan oleh 2 faktor, yakni faktor struktural; dan kultural. Aspek pokok yang dibahas dalam penelitian ini yakni Aspek spasial sebagai bagian dari faktor Struktural. Aspek spasial yang ditinjau dari kondisi permukiman. Kondisi permukiman yang padat, sempit, terbatasnya ruang gerak dan interaksi khususnya bagi anak-anak dan remaja dapat dikatakan sebagai faktor masalah utama penyebab tawuran. Penelitian ini berfokus pada identifikasi sebab munculnya isu bencana sosial tawuran tersebut dan kaitannya dengan permukiman kumuh perkotaan, disertai dengan usulan tindakan mitigasi spasial (arsitektur) yang sesuai. Kondisi lingkungan, kemiskinan dan proses eksklusi sosial berkaitan erat dengan potensi terjadinya konflik horizontal (Darmajanti, 2011).

\section{Metode Penelitian}

Lokasi penelitian berada di Kecamatan Johar Baru, Kotamadya Jakarta Pusat. Metode penelitian yang diterapkan pada penelitian ini adalah metode penelitian deskriptif-kualitatif . Permasalahan - permasalahan dilokasi didata kemudian digambarkan atau diceritakan kembali secara tersistematis untuk kemudian dianalisa. Metode analisa menggunakan analisa data primer dan sekunder. Hasil analisa akan menjadi acuan berpikir menuju solusi spasial terkait mitigasi bencana sosial yang dalam kasus ini menganggulangi terjadinya tawuran.

\section{Hasil dan Pembahasan}

\subsection{Densitas Spasial Permukiman Kec. Johar Baru}

Menurut Yockey (Suryo, 2017) kebutuhan luas ruang hunian berpengaruh terhadap kesehatan dan tingkat stress dari penghuninya. Menurut Suryo (2017) dalam penelitiannya mengenai "Analisa Kebutuhan Luas Minimal Pada Rumah Sederhana Tapak Di Indonesia” menyimpulkan bahwa luasan minimal untuk 
rumah tapak sederhana adalah $30.90 \mathrm{~m}^{2}-36 \mathrm{~m}^{2}$ (sirkulasi paling efisien dan kenyamanan secara ergonomi dan antropometrik). Berdasarkan pernyataan tersebut dapat diketahui bahwa standar minimum ruang huni per orang adalah $30.90 \mathrm{~m}^{2}$ dibagi 4 (2 Dewasa dan 2 Anak) yakni $7.725 \mathrm{~m}^{2} /$ jiwa. Jika kita bandingkan dengan data kepadatan penduduk menurut BPS maka :

Tabel 3.1 Luasan Rata-Rata Jiwa/m² Di Kec. Johar Baru

\begin{tabular}{|c|c|c|c|}
\hline Kelurahan & $\begin{array}{l}\text { Luas } \\
\text { Wilayah }\end{array}$ & $\begin{array}{l}\text { Kepadatan } \\
\text { Penduduk }\end{array}$ & $\begin{array}{l}\text { Luasan Rata- } \\
\text { Rata /Jiwa }\end{array}$ \\
\hline Johar Baru & $1.19 \mathrm{~km}^{2}$ & $38.431 / \mathrm{km} 2$ & $30.96 \mathrm{~m}^{2} /$ jiwa \\
\hline Kampung Rawa & $0.30 \mathrm{~km}^{2}$ & $91.330 / \mathrm{km} 2$ & $3.28 \mathrm{~m}^{2} /$ jiwa \\
\hline Tanah Tinggi & $0.62 \mathrm{~km}^{2}$ & $76.882 / \mathrm{km} 2$ & $8.06 \mathrm{~m}^{2} /$ jiwa \\
\hline Galur & $0.26 \mathrm{~km}^{2}$ & $89.357 / \mathrm{km} 2$ & $3.90 \mathrm{~m}^{2} /$ jiwa \\
\hline
\end{tabular}

Sumber : Johar Baru Dalam Angka, 2018

Kelurahan dengan kepadatan pemukim paling tinggi adalah kelurahan Kampung Rawa disusul Galur, Tanah Tinggi, dan Johar Baru. Untuk Tanah Tinggi dan Johar Baru masih berada dalam batasan standar luasan, namun untuk Kampung Rawa dan Galur terlihat jelas jauh dari standar. Keadaan ini membuat kedua kelurahan memiliki predikat dengan kepadatan permukiman tinggi (crowding).

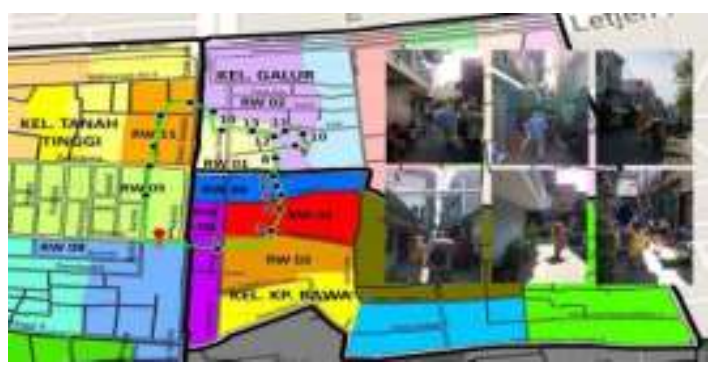

Gambar 4.1 Survey Kondisi Permukiman Kel. Kampung Rawa (RW 08;02;01;06)

Sumber: Data Pribadi Peneliti, 2018

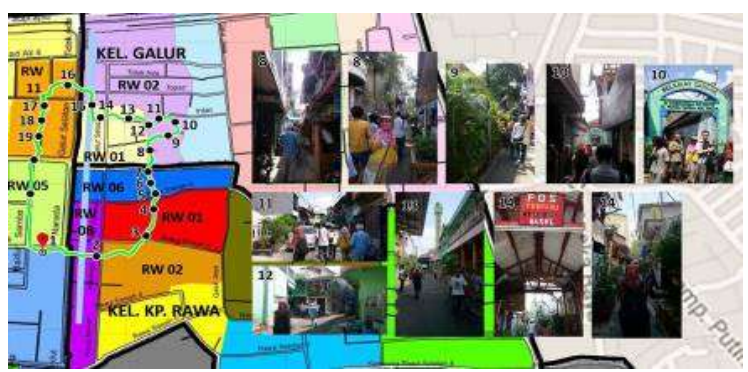

Gambar 4.2 Survey Kondisi Permukiman Kel. Galur (RW 01;02)

Sumber: Data Pribadi Peneliti, 2018

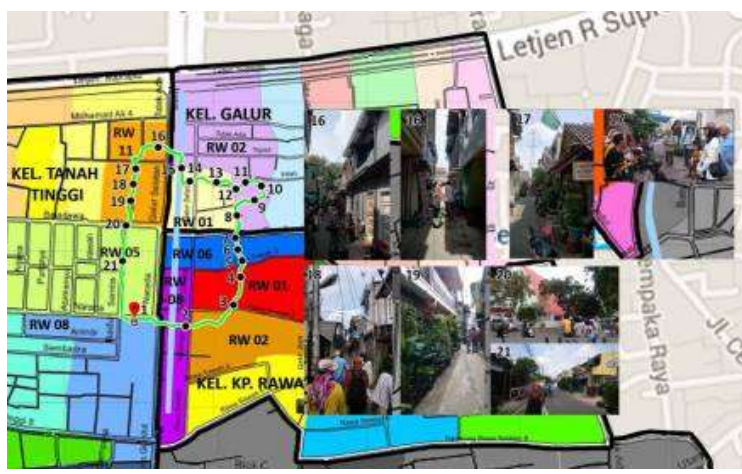

Gambar 4.3 Survey Kondisi Permukiman Kel. Tanah Tinggi (RW 11;05)

Sumber: Data Pribadi Peneliti, 2018 
Kepadatan permukiman di 3 kelurahan (Kampung Rawa, Galur, dan Tanah Tinggi) dikuatkan dengan penemuan Area Ruang Terbuka Hijau (RTH) seperti Lapangan Andepol, lapangan Kota Paris, Taman Kampung Rawa, dan Lapangan Basket. Namun, RTH tersebut tidak dapat leluasa dipakai oleh warga Johar Baru karena beberapa bertsatus tanah pribadi, lokasi yang tidak menarik (menurut warga) dan dimiliki oleh geng lawan. Kondisi inilah yang mendefinisikan kepadatan secara nyata di Permukiman Johar Baru. Kepadatan inilah yang dapat menimbulkan stress dan dapat dikatakan sebagai salah satu pemicu tawuran.

Berdasarkan survey (lihat gambar 4.4) lebar jalan permukiman kumuh yang ada di Johar Baru berkisar antara 1-1.5 m. Dikarenakan kondisi jalan permukiman warga yang sempit inilah, penyebab para pemuda dan remaja tidak mampu membentuk suatu ruang berkumpul atau ruang berinteraksi, maka mereka memanfaatkan jalan utama sebagai tempat berkumpul sehingga rentan provokasi berujung tawuran.
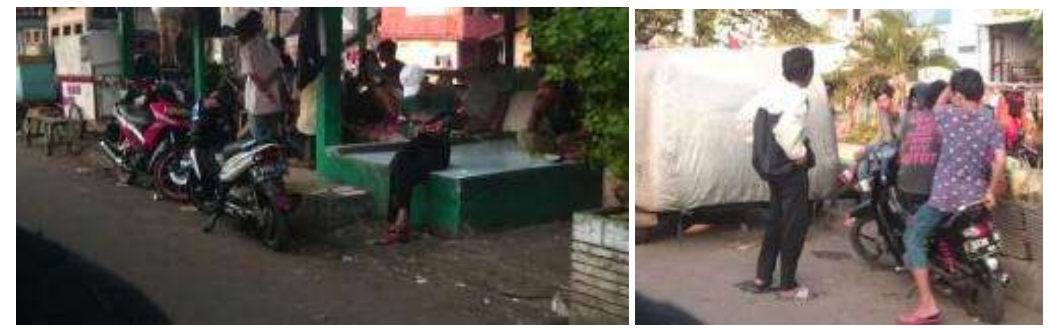

Gambar 4.4 Spot Nongkrong

Sumber: Data Pribadi Peneliti, 2018
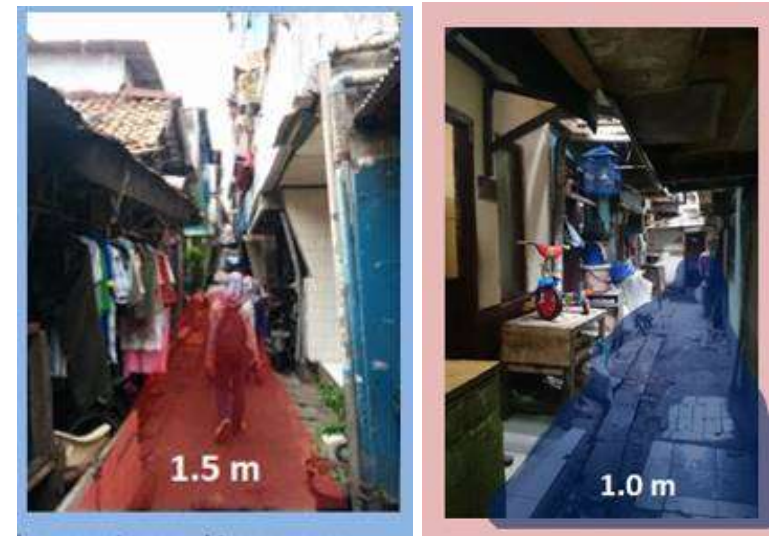

Gambar 4.4 Kondisi Jalan Permukiman

Sumber: Data Pribadi Peneliti, 2018

\subsection{Anatomi Tawuran}

Untuk dapat memahami lebih dalam mengenai perilaku tawuran sebagai bagian dari suatu konflik dapat menggunakan kerangka berpikir Krisberg (Yasmine, 2012) : (1) Isu (sumber masalah); (2)Karakteristik Pihak Berlawanan; (3) Relasi diantara pihak berlawanan; (4) Konteks yang membuat pihak berlawanan; (5) Sarana atau alat perlawanan; (6) Hasil Perlawanan. Yasmine (2012) telah melakukan penelitian terdahulu mengenai anatomi konflik di kawasan Johar Baru. Menggunakan 6 kerangka berpikir tersebut teridentifikasi fakta yakni :

1. Isu Permasalahan : (i) Percekcokan dalam interaksi sehari-hari warga khususnya anak muda (taruhan, percintaan, saling ejek); (ii) Provokasi bermotif ekonomi seperti menciptakan tawuran disekitar lahan bernilai tinggi agar nilainya turun, memberi kesan daerah kampong tawuran untuk mengundang datangnya bantuan sosial pemerintah

2. Karakteristik Pihak Tawuran : terjadi antara kelompok nongkrong usia muda 16-35 tahun, mayoritas belum bekerja, pendidikan putus sekolah pada SD, SMP, atau SMA/STM. Maslah utama diakibatkan faktor structural seperti terbatasnya ruang gerak tempat tinggal, sehingga mereka berinteraksi dipinggir jalan.

3. Pelaku Konflik : pelaku konflik adalah kumpulan kelompok nongkrong yang berseteru, adapun data jumlah kelompok nongkrong yakni 
Tabel 4.1 Data Kelompok Nongkrong

\begin{tabular}{|l|l|l|l|l|}
\hline No & Kampung Rawa & Johar Baru & \multicolumn{1}{|c|}{ Tanah Tinggi } & \multicolumn{1}{|c|}{ Galur } \\
\hline 1 & Sadigo & Kramat Raya & Gang 10 & Kopar \\
\hline 2 & Golday & PBR & Marjinal & Gang Intan \\
\hline 3 & Madesu & Gem-Vhal & Gambrenk & \\
\hline 4 & Perempatan Sajab & Boderex & Baladewa & \\
\hline 5 & Kuman & Kawi-kawi atas & Bambu Kuning & \\
\hline 6 & Bengal & Kawi-Kawi & Lap One & \\
& & & & \\
\hline 7 & Rasela & Pantai & Tanti 12 & \\
\hline 8 & Amunka & Sengon & Tamper & \\
\hline 9 & Bocires & Bomber & Andepol & \\
\hline 10 & Badai & Oblack & Margalung & \\
\hline 11 & Kunci & Kalonk & Panti & \\
\hline 12 & Lepoy & Amle & Abapon & \\
\hline 13 & Caplin & Joker 5 & grafik & \\
\hline 14 & Boltacus & Bonawi & Pulo Gundul & Sumber : Yasmine, 2012 \\
\hline 15 & Bonekar & & Andesa & Velback \\
\hline 16 & Gogat & & Beraza & \\
\hline 17 & Kawah & \multicolumn{2}{|l|}{}
\end{tabular}

4. Konteks Berlawanan : (i) aspek spasial-kondisi permukiman yang sempit, padat membuat terbatasnya ruang gerak dan interaksi antar warga. (ii) Aspek kelembagaan seperti karang taruna belum maksimal merangkul kalangan yang berada di "bawah" (putus sekolah, miskin, dsb.) secara stratifikasi sosial. (iii) Faktor kultural adalah kurangnya perhatian dan kasih saying orang tua sehingga nongkrong menjadi budaya bagi anak muda, demikian pula tawuran.

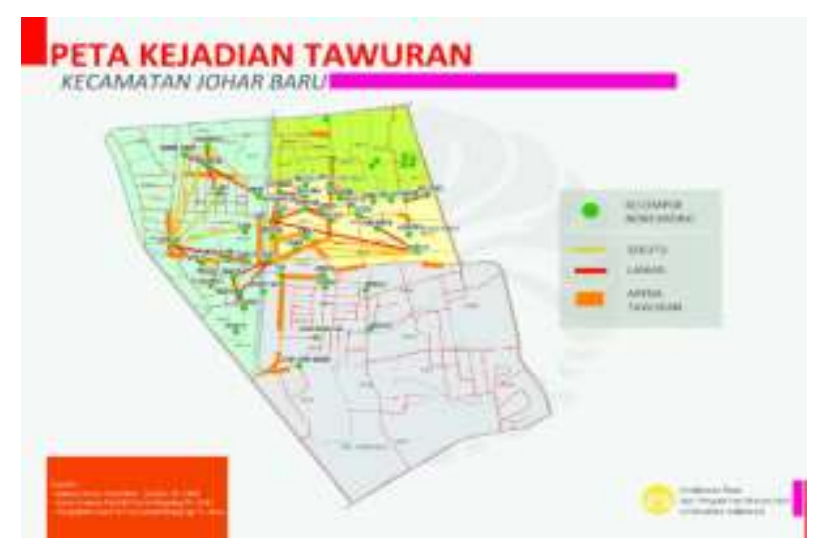

\section{Gambar 4.6 Peta Kelompok Nongkrong dan Titik Tawuran}

Sumber: Yasmine, 2012

5. Lokasi, Waktu, dan Peralatan : arena tawuran berada pada jalan utama ( lihat Gambar 4.6). Sebagian besar arena tawuran ada pada Kampung Rawa, dengan kelompok nongkrong terbanyak. Rentang waktu tawuran terjadi pada malam hari sehabis maghrib hingga dini hari. Peralatan yang digunakan seperti Molotov, golok parang, neon bekas, bamboo, pecahan botol, dll.

6. Dampak atau Hasil : Stigmatisasi warga johar baru sebagai simbol negativitas dan merusak. Korban jiwa dan materiil (rusaknya fasilitas).

Berdasarkan anatomi oleh Yasmine (2012). Dapat diketahui bahwa tawuran memiliki dampak buruk terhadap pelaku dan lingkungannya yang mana sumber masalah utama adalah densitas spasial (Minimnya Ruang Gerak dan Interaksi). Densitas spasial ini mengantar pada konklusi bahwa permukiman kumuh johar baru erat akan isu Eksklusi Sosial (Tempat Tinggal Tak Layak, Berpenghasilan Rendah, Putus Sekolah, dsb.) penyebab terjadinya tawuran. 


\subsection{Tipikal Hunian Warga}

Salah satu hunian yang diangkat sebagai contoh yaitu, terletak di JL. Kramat Raya. Rumah 2 Lantai ini, memiliki ruang yang sangat terbatas. LT. Dasar diperuntukkan sebagai area hunian berkapasitas 4 orang dan area dagang, sedangkan LT.2 disewakan sebagai kos-kosan dengan kapasitas 3 orang. Rumah ini memiliki luas kurang lebih $9 \mathrm{~m} 2(3 \times 3 \mathrm{~m})$. Rata-rata pada permukiman kumuh Johar Baru satu orang menempati $4.6 \mathrm{~m} 2$ ruang sebagai tempat bermukim. Angka tersebut berada dibawah standar yakni $8.025 \mathrm{~m} 2 /$ orang (Suryo, 2017).
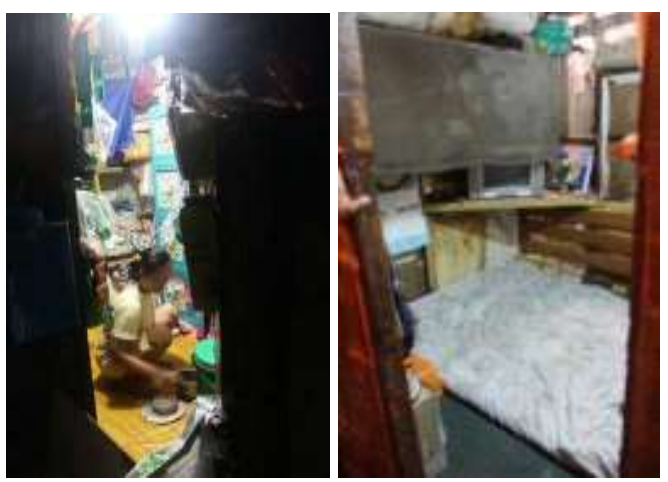

Gambar 4.5 Sampel Tipikal Rumah Kumuh Kampung Rawa Sumber: Data Pribadi Peneliti, 2018

Terpahami bahwa kondisi tipikal rumah tinggal yang sempit, sangat tidak mampu mendukung aktivitas dan standar kenyamanan bagi manusia yang berkegiatan di dalamnya. Kondisi minimnya luas ruang dalam rumah tinggal contoh mewakili hampir sebagian besar tipologi rumah-rumah kumuh yang ada di kecamatan Johar Baru Khususnya Kampung Rawa dan Galur. Kondisi ini ditekankan keparahannya dengan fakta bahwa terjadi praktik memakai ruang dalam rumah untuk tidur secara bergantian. Hal tersebut ditekankan dengan pernyataan warga (Informan X):

"Ya kalau orang tuanya tidur malam, anaknya di luar rumah nongkrong atau pegi kemane.. nah kalo uda pagi baru tuh anak-anaknye pada tidur".

Berdasarkan perkataan warga, dapat dipahami bahwa aktivitas nongkrong juga terjadi pada malam hari dan bahkan lebih rawan timbul tawuran dikarenakan kondisi pemuda yang lelah sehabis bekerja namun tidak dapat bersitirahat, sehingga cepat stress dan emosi meluap.

\subsection{Solusi Mitigasi Spasial Tawuran}

Berdasarkan identifikasi permasalahan, disimpulkan bahwa faktor struktural, yakni aspek spasial dalam konteks ruang gerak dan ruang berinteraksi yang sangat minim menjadi masalah utama. Ketersediaan lahan yang dapat dimanfaatkan sebagai mitigasi spasial bencana tawuran juga hampir tidak ditemukan akibat densitas spasial permukiman yang sangat tinggi. Solusi spasial berprinsip mobile (dapat berpindah-pindah) dan fleksibel (dapat diterapkan dimana saja) sebagai solusinya.

\subsubsection{Menghadirkan Kegiatan dengan Box Ekspresi}

Problem Focused Coping strategy diterapkan melalui menciptakan area untuk mengasah ketrampilanketrampilan baru bagi anak muda kelompok nongkrong sarat tawuran Kec. Johar Baru, sehingga mereka jauh dari pemikiran tawuran (akibat stress tekanan lingkungan) dan membuat mereka mendekat ke pemikiran serta tindakan-tindakan postif bermanfaat. 


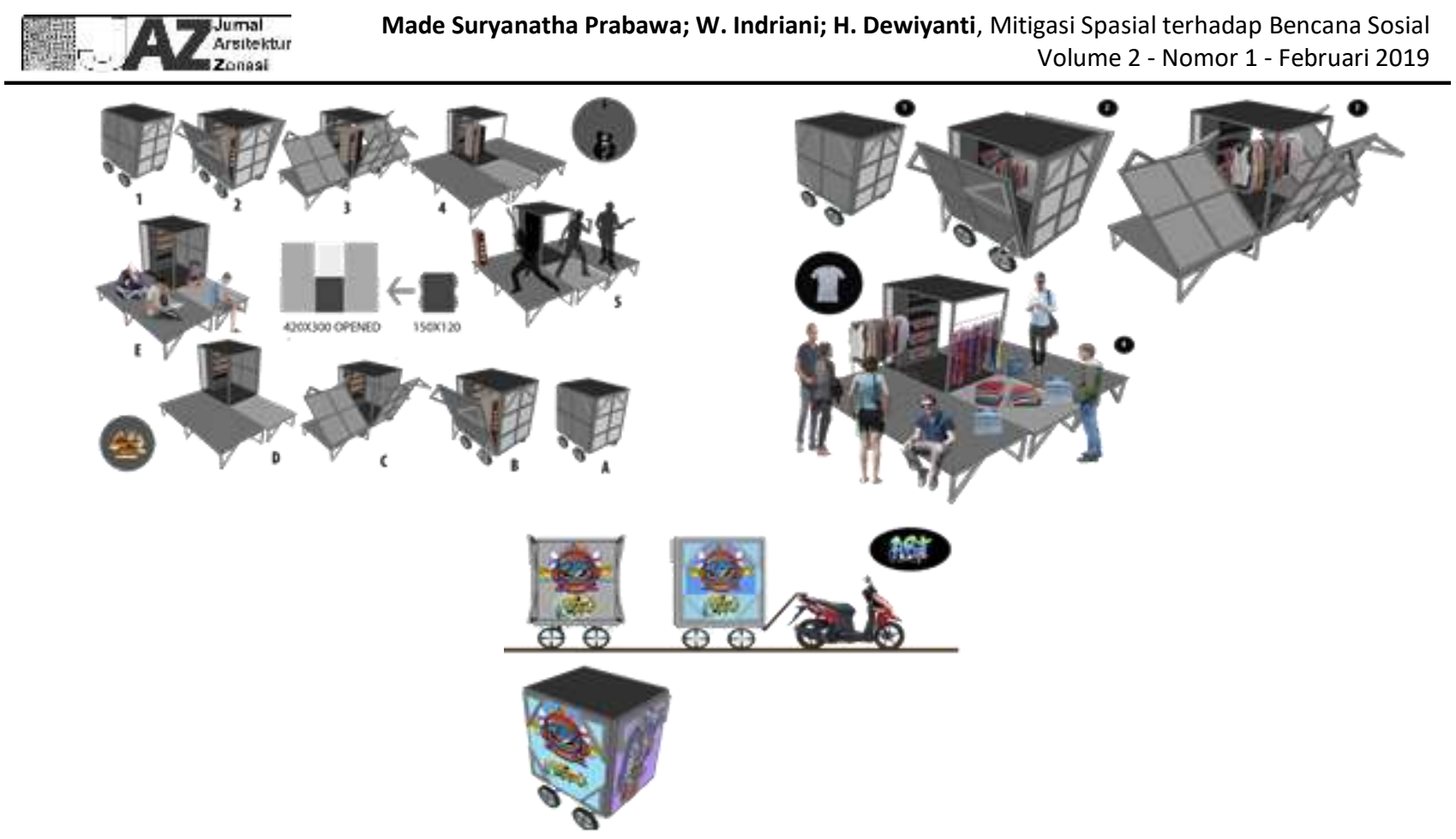

\section{Gambar 4.6 Sistem Penggunaan dan Pemanfaatan Box Ekspresi}

Sumber: Data Pribadi Peneliti, 2018

Coping strategy berpinsip mobile dan berbentuk portable architecture yakni Box Ekspresi (BOXi) diusulkan. Box ekspresi ini dapat memiliki banyak manfaat seperti :

1. Sebagai sarana untuk pagelaran (Musik, Stand Up Comedy, dll)

2. Sarana pemberdayaan masyarakat secara "Penyuluhan Mobile"

3. Perpustakaan Keliling

4. Sarana Berjualan Usaha Kecil Menengah (Distro Keliling, Alat Tulis, dll.)

5. Lukis Mural atau Grafitti

Dengan demikian terdapat sarana penyaluran aktivitas positif bagi para anak muda kelompok nongkrong. Pengadaan Box Ekspresi ini dapat diterapkan di masing-masing kelurahan pada setiap Karang Taruna. Untuk titik-titik penggunaan dapat memanfaatkan bahu atau badan jalan. Karakteristik ukuran box ekspresi yang efisien dan dapat berpindah-pindah membuatnya dapat dimanfaatkan dimana saja dan kapan saja.

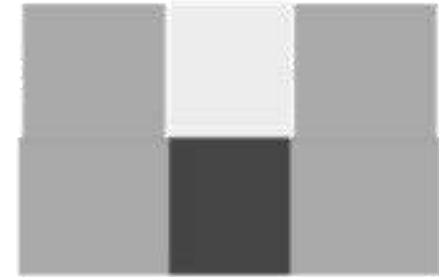

420X300 OPENED

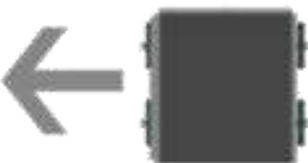

$150 \times 120$

\section{Gambar 4.7 Denah Box Ekspresi (BOXi) \\ Sumber: Data Pribadi Peneliti, 2018}

BOXi (Box Ekspresi) terdiri dari 6 modul yang dapat dilipat menjadi 1 modul.Saat digunakan sebagai panggung pertunjukan, masing-masing modul dapat digunakan 5 personel band, sedang 1 modul sisanya yang beratap dapat digunakan sebagai tempat untuk meletakkan amplyfier dan alat-alat lainnya. Modul Dasar menggunakan ukuran 1,2 x 1,5 m. Ukuran lebar 1,2 menyesuaikan dengan ukuran standard papan Plywood (1,2 x 2,4 m), agar penggunaan bahan dapat lebih efisien.

Sedangkan ukuran $1,5 \mathrm{~m}$ pada panjang, digunakan karena ukuran tersebut terbukti stabil pada motor 'Viar'. Terdapat 3 varian modular yang dapat diterapkan pada BOXi. Varian modular ini dimaksudkan agar BOXi dapat menyesuaikan dengan berbagai kondisi lingkungan yang ada, yaitu mulai dari varian 1 yang 
dapat diaplikasikan pada site yang luas (lapangan), hingga varian 3 yang dapat diaplikasikan pada jalan yang sempit.

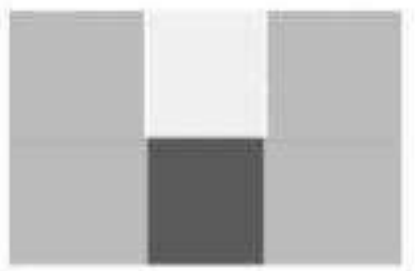

1

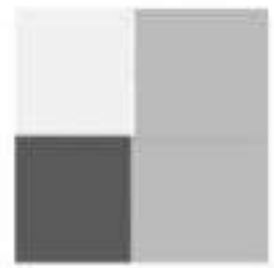

2
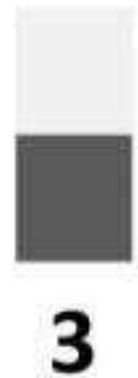

Gambar 4.8 Varian Modul Box Ekspresi (BOXi)

Sumber: Data Pribadi Peneliti, 2018

\subsubsection{Mitigasi Spasial dengan Vertikultur}

Peningkatan kualitas kehidupan manusia dapat dicapai melalui dampak positif Vertikultur / taman vertikal (Gulcinay \& Arzu, 2016), seperti : (1) Konservasi Energi; (2) Pengurangan Karbondioksida; (3)Produksi Oksigen; (4)Pengurangan Polusi Suara; (5)Habitat Untuk Kehidupan Liar (serangga, dsb); (6)Penyaringan Partikel; (7) Pertanian Perkotaan; (8) Dampak Positif Pada Manusia.

Kedelapan faktor tersebut berujung pada dampak sosial, khususnya pada aspek psikologis yang mengacu pada pengurangan kadar stress, ketakutan, kemarahan,dsb. menggunakan media hortikultura (Brown K., 2004). Taman Vertikal juga mampu menurunkan pikiran negative dan membantu meditasi (Peck, 1999). Berdasarkan penelitian oleh Gulcinay (2016) diketahui betapa bermanfaatnya vertical garden bagi usaha penciptaan lingkungan yang nyaman, tenang, dan asri sehingga berdampak pada berkurangnya stress akibat densitas spasial berujung pada berkurangnya intensitas tawuran. Selain memberi pengaruh psikologis kesempatan berwirausaha dapat diciptakan melalui pertanian perkotaan (urban farming) dengan berbasis karang taruna, sehingga kelompok nongkrong sarat tawuran dapat memiliki peluang berwirausaha sayur mayur dengan memanfaatkan lahan seadanya ditengah densitas spasial permukiman kumuh Johar Baru.
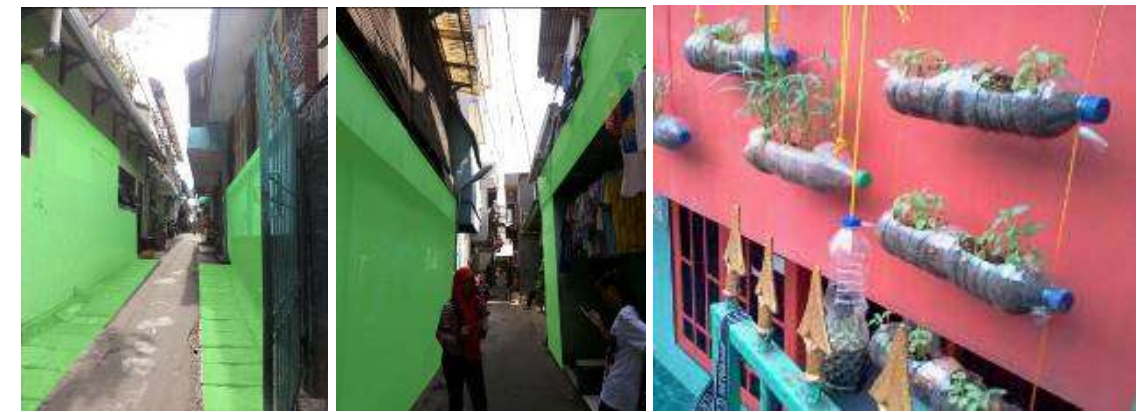

Gambar 4.9 Area Hijau sebagai Area Penerapan Vertical Garden

Sumber: Data Pribadi Peneliti, 2018

Penerapan dapat memanfaatkan dinding-dinding sekitar gang / jalan tempat nongkrong sehingga aktivitas nongkrong dapat berubah menjadi merawat tanaman. Dinding rumah masing-masing warga juga dapat digunakan (lihat gambar 4.11) sehingga permukiman Johar Baru secara keselurahan (tidak hanya lokasi kelompok nongkrong) dapat memberikan suasana permukiman yang hijau dan nyaman, serta mendukung peningkatan ketenangan dan penurunan stress akibat densitas spasial.

\section{Kesimpulan}

Secara keseluruhan mitigasi spasial tidaklah cukup, karena permasalahan tidak hanya menyangkut aspek spasial namun juga sosial. Aspek sosial perlu untuk ditangani melalui mitigasi sosial berupa pemberdayaan, pembekalan yang mampu memberikan anak muda kelompok nongkrong sebuah kemampuan. Kemampuan yang dapat mereka gunakan untuk mencari nafkah dan bersosialisasi dengan lebih baik, sehingga terhindar dari tawuran. Coping strategy melalui Mitigasi spasial dengan prinsip mobile dan fleksibel dalam bentuk 
Box Ekspresi ( Portable Architecture) dan Vertikultur diharapkan mampu memberi peluang beraktivitas lebih baik bagi para anak muda kelompok nongkrong. Usulan ini mungkin tidak sepenuhnya dapat menuntaskan tawuran, namun jika diterapkan dengan maksimal, niscaya tawuran akan dapat berkurang.

\section{Referensi}

Brown K., B. A. (2004). Health Benefits of Urban Agriculture Retrieved From Community Food Security Coalition.

Darmajanti, L., Wirutomo, P., Ery Seda, F., \& Yasmine, D. (2012). Twuran, Kemiskinan, dan EKsklusi Sosial : Suatu Studi Kasus Mengenai Konflik Horizontal di Kecamatan Johar Baru, Kotamadya Jakarta Pusat. Depok: Hibah Riset: Utama UI (RU-UI).

Gulcinay, B., \& Arzu, C. (2016). Ecological-Social-Economical Impacts of Vertical Gardens in the Sustainable City Model. YYU TAR BIL DERG, 26 (3), 430-438.

Haryadi, S. B. (2014). Arsitektur, Lingkungan, dan Perilaku. Yogyakarta: Gadjah Mada University Press.

Peck, S. C. (1999). Greenbacks from Green Roofs: Forging a New Industry in Canada, Final Report. Canadian Mortage and Housing Corperation.

Suryo, M. S. (2017). Analisa Kebutuhan Luas Minimal Pada Rumah Sederhana Tapak di Indonesia. Jurnal Permukiman Vol.12 No.2 November 2017, 116-123.

Yasmine, D. I. (2012). Anatomi Tawuran Antar Kelompok Pemuda. Jakarta.

https://megapolitan.kompas.com/read/2017/04/25/18311031/polisi.babak.belur.saat.melerai.tawuran.di.johar. baru. (Akses 5 Desember 2018)

https://megapolitan.kompas.com/read/2017/09/03/15152391/tawuran-di-johar-baru-polisi-tetapkan-10warga-jadi-tersangka, (Akses 5 Desember 2018)

https://www.suara.com/news/2017/12/07/005213/stop-tawuran-kapolsek-johar-baru-sarankan-ini-kekampung-rawa, (Akses 5 Desember 2018) 